\title{
Host Specificity of Ascochyta spp. Infecting Legumes of the Viciae and Cicerae Tribes and Pathogenicity of an Interspecific Hybrid
}

\author{
M. A. Hernandez-Bello, M. I. Chilvers, H. Akamatsu, and T. L. Peever
}

Department of Plant Pathology, Washington State University, Pullman 99164.

Current address of M. A. Hernandez-Bello: Department of Plant Pathology, University of California, Davis 95616.

Accepted for publication 6 June 2006.

\begin{abstract}
Hernandez-Bello, M. A., Chilvers, M. I., Akamatsu, H., and Peever, T. L. 2006. Host specificity of Ascochyta spp. infecting legumes of the Viciae and Cicerae tribes and pathogenicity of an interspecific hybrid. Phytopathology 96:1148-1156.

Ascochyta spp. (teleomorphs: Didymella spp.) infect a number of legumes, including many economically important species, and the diseases they cause represent serious limitations of legume production worldwide. Ascochyta rabiei, A. fabae, A. pisi, A. lentis, and A. viciae-villosae are pathogens of chickpea (Cicer arietinum), faba bean (Vicia faba), pea (Pisum sativum), lentil (Lens culinaris), and hairy vetch (V. villosa), respectively. Inoculations in the greenhouse and in growth chambers demonstrated that A. fabae, A. lentis, A. pisi, A. rabiei, and A. viciaevillosae were host specific. Isolates caused no visible disease symptoms on "nonhost" plants (plants other than the hosts they were originally isolated from) but were recovered consistently from inoculated, surfacedisinfested, nonhost tissues. Interspecific crosses of A. pisi $\times$ A. fabae and A. viciae-villosae $\times$ A. lentis produced pseudothecia with viable ascospores, and the hybrid status of the ascospore progeny was verified by the

(AFLP) markers. Interspecific progeny were morphologically normal in culture but exhibited more phenotypic variation compared with progeny from intraspecific crosses. Mating type and the majority of AFLP markers segregated in Mendelian 1:1 ratios in both intraspecific and interspecific crosses. A total of 11 and 7\% of AFLP markers showed segregation distortion among progeny from interspecific crosses and intraspecific crosses, respectively; however, this difference was not significant $(P=$ $0.90)$. Only 30 of 114 progeny isolates from the A. fabae $\times A$. pisi cross inoculated in the greenhouse caused lesions on pea and only 4 caused disease on faba bean. In all, 15 of 110 progeny isolates were pathogenic to pea and none were pathogenic to faba bean under growth chamber conditions. Although no obvious postzygotic, intrinsic isolating barriers were identified in any of the interspecific crosses, it appears that host specialization may act as both a prezygotic, ecological isolating barrier and a postzygotic, extrinsic, ecological isolating barrier in these fungi. Host specificity, coupled with low pathogenic fitness of hybrids, may be an important speciation mechanism contributing to the maintenance of hostspecific, phylogenetic lineages of these fungi.
\end{abstract} segregation of mating type and amplified fragment length polymorphism

Ascochyta spp. (teleomorphs: Didymella spp.) infect a number of economically important legumes, and the diseases they cause represent serious limitations to legume production worldwide. Ascochyta fabae Speg., A. lentis Vassiljevsky, A. pisi Lib., A. rabiei (Pass) Labr., and A. viciae-villosae Ondrej are pathogens of faba bean (Vicia faba L.), pea (Pisum sativum L.), lentil (Lens culinaris Medik.), chickpea (Cicer arietinum L.), and hairy vetch (Vicia villosa Roth), respectively $(27,36,42,43)$. The taxonomy of Ascochyta spp. is based primarily on morphological characters such as the shape and size of conidia and conidial septation, and secondarily on host of isolation and molecular markers $(13,17$, 28). It is possible to perform in vitro crosses of Ascochyta spp. $(60,65)$, which has allowed application of the biological species concept. Previous crosses of $A$. rabiei with either A. fabae or $A$. lentis failed to produce pseudothecia, but crosses between $A$. fabae and $A$. lentis produced pseudothecia with viable ascospores (28). Ascospore progeny from this cross had anomalies in growth morphology and nonstandard numbers of ascospores per ascus, and were not pathogenic to either faba bean or lentil. These results suggested that A. rabiei may be more distantly related to A. fabae and $A$. lentis than the latter species were to each other, and that A. fabae and A. lentis were each distinct biological species (28).

Phylogenetic analysis of legume-associated Ascochyta spp. using nuclear ribosomal internal transcribed spacer (ITS) sequence

Corresponding author: T. L. Peever; E-mail address: tpeever@wsu.edu

DOI: 10.1094/PHYTO-96-1148

(C) 2006 The American Phytopathological Society
Additional keywords: fungal speciation, host range, hybridization. data supports the monophyly of Ascochyta/Didymella, but does not provide sufficient resolution to distinguish Ascochyta spp. on different legume hosts $(1,47,49,50)$. In contrast, phylogenies estimated from the high-mobility-group region (HMG-box) of the MAT1-2 mating idiomorph, glyceraldehyde-3-phosphate-dehydrogenase $(G 3 P D)$, translation elongation factor 1 alpha $(E F)$, and chitin synthase $1(C H S)$ revealed that multiple, geographically distinct isolates from each host were found in well-supported clades, suggesting that Ascochyta fungi causing disease on each host can be considered phylogenetic species $(1,49)$. These analyses also revealed that $A$. rabiei is distantly related to other Ascochyta spp. on legumes, whereas $A$. fabae is most closely related to $A$. pisi and A. lentis is most closely related to A. viciaevillosae. Thus, the phylogenetic analyses support the results of crosses made by Kaiser et al. (28) and have led to the hypothesis that Ascochyta biological species are also phylogenetic species $(1,49)$.

The basis of parasite-host specificity in fungal-plant interactions has been investigated extensively, but is only well understood at the molecular level in a few pathosystems $(46,55)$. Heath $(18,19)$ distinguishes two types of host specificity: species specificity, which determines host species range and may be genetically complex, and cultivar specificity, which governs specificity within a given host species and frequently is controlled by single genetic loci in both pathogen and host in gene-for-gene fashion. Little is understood about the genetic and molecular basis of host species specificity compared with cultivar specificity; however, genetic crosses between sibling species have provided support for the hypothesis that gene-for-gene systems also may 
govern host species specificity at the species level $(6,9,39-$ 41,57,58). Host specialization frequently is associated with genetic incompatibilities (postmating, postzygotic, intrinsic isolating barriers) that may be important in speciation $(3,31)$. However, this prediction may not hold for many plant-pathogenic fungi because they often retain the ability to mate but demonstrate greatly reduced fitness when inoculated on their hosts $(15,31,53,56)$. Evidence for fungal hybridization in nature is limited (5), but laboratory crosses and cytological, biochemical, and molecular data suggest that many plant-associated fungi and Stramenopiles have the potential for hybridization $(4,44,56)$. Although hybridization of fungal pathogens in the laboratory can assess the potential for gene flow $(15,53)$, there is still much debate regarding how in vitro crosses should be interpreted in terms of the significance of species hybrids in nature (52). Interspecific hybridization of fungal pathogens is also of practical importance because it increases genotypic diversity and may result in taxa with a wider host range or better adapted to new environments, possibly changing disease epidemiology and disease management practices (38). The objectives of this study were to (i) determine the host specificity of closely related, legume-associated Ascochyta spp.; (ii) determine the hybrid status of progeny from intraspecific and interspecific crosses using molecular markers; (iii) estimate the strength of intrinsic postzygotic mating barriers between species by comparing the segregation distortion of molecular markers between intraspecific and interspecific crosses; and (iv) evaluate host specificity as an extrinsic, postzygotic mating barrier by estimating the pathogenic fitness of ascospore progeny from an interspecific cross.

\section{MATERIALS AND METHODS}

Fungal isolates. Single-conidial isolates of A. fabae, A. pisi, A. lentis, A. viciae-villosae, and A. rabiei were obtained from the United States Department of Agriculture (USDA) Western Region Plant Introduction Station, Pullman, WA (Table 1). Previous phylogenetic analyses revealed that these fungi, each isolated from a specific legume host, consistently fell into well-supported clades $(1,49)$. Therefore, we considered each host-associated fungus employed in this study to represent a species under the phylogenetic species recognition concept (59). A previous study also demonstrated that $A$. fabae and A. lentis are biological species (28). Isolates were cultured on V8 juice agar $(200 \mathrm{ml}$ of V8 juice, $3 \mathrm{~g}$ of $\mathrm{CaCO}_{3}$, and $20 \mathrm{~g}$ of agar per liter) and incubated at $22^{\circ} \mathrm{C}$ under fluorescent light with a 12-h photoperiod. Liquid cultures were initiated with 4-mm ${ }^{2}$ pieces of filter paper in 2-YEG (2 $\mathrm{g}$ of yeast extract and $10 \mathrm{~g}$ of glucose per liter) and incubated at $25^{\circ} \mathrm{C}$ on a rotary shaker at $175 \mathrm{rpm}$ for 4 to 6 days. Mycelia were collected by filtration, lyophilized, and powdered, and DNA was extracted using the method of Lee and Taylor (32). DNA concentration was quantified using a Fluoromark microplate fluorometer (Bio-Rad Laboratories, Hercules, CA).
Mating type determination. Mating type-specific polymerase chain reaction (PCR) was used to select parental isolates for crosses and to determine the hybrid status of ascospore progeny. For progeny from the $\mathrm{AP} 1 \times \mathrm{AP} 2, \mathrm{AF} 1 \times \mathrm{AF} 3, \mathrm{AF} 3 \times \mathrm{AP} 4$, and AL1 $\times$ AV22 crosses, mating type was determined using a multiplex PCR assay designed to amplify the MAT idiomorphs from A. lentis, A. fabae, A. pisi, and A. viciae-villosae similar to that developed for $A$. rabiei by Barve et al. (1). The three primers used in the assay included MAT1-1-specific (GCAACATCCTAGCATGATG), MAT1-2-specific (CTGTCTCACCCAAGGCAAAC), and common 3' flanking (CACATCACCCCACAAGTCAG) (M. I. Chilvers and T. L. Peever, unpublished data). PCR was carried out in 20- $\mu \mathrm{l}$ volumes containing $10 \mathrm{ng}$ of DNA, $1 \times$ PCR buffer $\left(20 \mathrm{mM}\right.$ Tris- $\mathrm{HCl}, 10 \mathrm{mM} \mathrm{KCl}, 10 \mathrm{mM}\left(\mathrm{NH}_{4}\right)_{2} \mathrm{SO}_{4}, 2 \mathrm{mM}$ $\mathrm{MgSO}_{4}$, and $0.1 \%$ Triton X-100) (New England Biolabs, Beverley, MA), $200 \mu \mathrm{M}$ dNTPs (New England Biolabs), $500 \mathrm{nM}$ each primer (Operon Technologies, Alameda, CA), and $1 \mathrm{U}$ of Taq polymerase (New England Biolabs). PCR was performed in a My-Cycler thermal cycler (Bio-Rad) with an initial denaturation step at $95^{\circ} \mathrm{C}$ for $3 \mathrm{~min}$, followed by 35 cycles of $94^{\circ} \mathrm{C}$ for $20 \mathrm{~s}$, $58^{\circ} \mathrm{C}$ for $20 \mathrm{~s}$, and $72^{\circ} \mathrm{C}$ for $40 \mathrm{~s}$, and a final extension step at $72^{\circ} \mathrm{C}$ for $10 \mathrm{~min}$. For progeny from the AP1 $\times$ AF1 cross, MAT1-2 idiomorphs were amplified using the degenerate HMG boxspecific primers HMG-8 and HMG-236 (1), and MAT1-1 idiomorphs were amplified using the $A$. rabiei MAT1-1-specific primer SP21 (1) and a common A. rabiei/A. lentis 3' flanking primer ALARComR2 (CCAGGNNTTCNAGACCAGGGT) (M. I. Chilvers and T. L. Peever, unpublished data). Because each isolate was screened against both MAT1-1-specific and MAT1-2specific primer pairs in separate PCRs, complementary amplification with one primer pair and not the other or vice versa provided a robust marker for mating type. PCR was carried out using the same thermal cycler and reaction conditions as described above for the mating type multiplex PCR except the program cycles for HMG8L and HMG-236R primers were $95^{\circ} \mathrm{C}$ for $3 \mathrm{~min}$, followed by 40 cycles of $94^{\circ} \mathrm{C}$ for $20 \mathrm{~s}, 55^{\circ} \mathrm{C}$ for $20 \mathrm{~s}$, and $72^{\circ} \mathrm{C}$ for $30 \mathrm{~s}$, and a final extension step at $72^{\circ} \mathrm{C}$ for $10 \mathrm{~min}$; and for the SP2 1 and ALARComR 2 primers conditions were $95^{\circ} \mathrm{C}$ for $3 \mathrm{~min}$, followed by 40 cycles of $94^{\circ} \mathrm{C}$ for $20 \mathrm{~s}, 50^{\circ} \mathrm{C}$ for $20 \mathrm{~s}$, and $72^{\circ} \mathrm{C}$ for $120 \mathrm{~s}$, and a final extension step at $72^{\circ} \mathrm{C}$ for $10 \mathrm{~min}$.

Plant materials. Chickpea cv. Spanish White, faba bean cv. Broad Windsor, lentil cv. Eston, pea cv. Lifter, and hairy vetch cv. Vivi line 8 were used for inoculation assays. All seed except faba bean were obtained from the USDA Agricultural Research Service Grain Legume Genetics and Physiology Research Unit or the Western Region Plant Introduction Station at Washington State University. Faba bean seed were obtained from Mountain Valley Seed Inc. (Salt Lake City, UT). Plants inoculated in the greenhouse were grown for 2 weeks in 25-by-6-cm conical plastic pots containing Sunshine Professional Growing Mix (Sun Gro Horticulture, Bellevue, WA) at $20 \pm 2{ }^{\circ} \mathrm{C}$. One seed was planted per pot and eight replicate pots were inoculated randomly with

TABLE 1. Isolates of Ascochyta spp. used in interspecific and intraspecific crosses, marker segregation, and inoculation assays

\begin{tabular}{|c|c|c|c|c|c|c|}
\hline Species & Host & Isolate code & ATCC accession $^{\mathrm{a}}$ & Mating type ${ }^{b}$ & Origin & Collector \\
\hline Ascochyta rabiei & Cicer arietinum & AR20 & 76501 & $M A T 1-2$ & Idaho, United States & W. J. Kaiser \\
\hline A. rabiei & Cicer arietinum & AR21 & 76502 & MAT1-1 & Idaho, United States & W. J. Kaiser \\
\hline A. rabiei & Vicia faba & AR735 & 201627 & MAT1-2 & Terbol, Lebanon & R. S. Malhotra \\
\hline A. fabae & Vicia faba & $\mathrm{AF} 1$ & 96418 & MAT1-2 & Saskatoon, Canada & B. Vandenberg \\
\hline A. fabae & Vicia faba & AF3 & $\ldots$ & MAT1-1 & Afghanistan & W. J. Kaiser \\
\hline A. pisi & Pisum sativum & AP1 & 201617 & MAT1-1 & Bulgaria & W. J. Kaiser \\
\hline A. pisi & Pisum sativum & AP2 & 201618 & MAT1-2 & Poznan, Poland & E. Swiecicki \\
\hline A. pisi & Pisum sativum & AP4 & 210620 & MAT1-2 & Saskatoon, Canada & B. Gossen \\
\hline A. lentis & Lens culinaris & AL1 & 96419 & MAT1-2 & Australia & W. J. Kaiser \\
\hline A. lentis & Lens culinaris & AL2 & 96420 & MAT1-1 & Brazil & W. J. Kaiser \\
\hline A. viciae-villosae & Vicia villosa & AV22 & $\ldots$ & MAT1-1 & Aprilci, Bulgaria & W. J. Kaiser \\
\hline
\end{tabular}

a American Type Culture Collection.

b Mating type determined by MAT-specific polymerase chain reaction with high-mobility-group region-specific (MAT1-2) primers (1). 
each fungal isolate for the host specificity tests, whereas four replicate pots were inoculated for pathogenicity tests of ascospore progeny isolates. Plants inoculated in the growth chambers were grown for 2 weeks in the greenhouse in 15-by-13-cm plastic pots containing Sunshine Mix as described above. Four to six and three to eight faba bean and pea seed were planted per pot, respectively. Two replicate pots were inoculated with each ascospore progeny isolate and pots were randomized over two growth chambers.

Host specificity assays. Ascochyta spp. were inoculated to 2-week-old plants of each legume species grown in the greenhouse under natural light with a 12- to 14-h photoperiod and temperatures of $20 \pm 2{ }^{\circ} \mathrm{C}$. Inoculations were performed in the evening to maximize leaf wetness periods and promote infection. Conidia were collected from 2 -week-old cultures of each isolate with a sterile spatula, spread over a fresh V8 agar plate, and incubated for 7 days at $22^{\circ} \mathrm{C}$ under fluorescent light with a 12-h photoperiod. Conidia were collected by washing the agar surface with sterile distilled water and scraping gently with a glass rod. Conidial suspensions were adjusted to $1 \times 10^{6}$ conidia $/ \mathrm{ml}$ using a hemacytometer and $0.03 \%$ (vol/vol) Tween 20 (Sigma-Aldrich, St. Louis) added as a wetting agent. Each conidial solution $(100 \mu \mathrm{l})$ was spread on $3 \%$ water agar (WA) plates and germination rates of 100 randomly selected conidia were assessed $24 \mathrm{~h}$ later. All Ascochyta isolates were inoculated simultaneously on all legume species. Plants were sprayed to runoff with each spore suspension using a hand sprayer and control plants were sprayed with sterile distilled water with $0.03 \%$ Tween 20 . Inoculated and control plants were covered with $600-\mathrm{ml}$ plastic cups for $48 \mathrm{~h}$ to maintain leaf wetness (7) and randomized over the greenhouse benches in a completely randomized design. Inoculation of each isolate was repeated at least once. Disease symptoms were evaluated 2 weeks after inoculation using a modified chickpea Ascochyta blight rating scale of 0 to 9 (8) where $0=$ no visible lesions; 1 = lesions visible; 2 = a few lesions visible; 3 = many lesions visible; 4 = large lesions on stem or leaves, some leaf and stem girdling; 5 = many large lesions on stem and leaves, moderate stem and leaf girdling; $6=$ many large lesions on stem and leaves, stem and leaf girdling common; $7=$ large lesions on stem and leaf common, stem and leaf girdling common; $8=$ severe lesions such that plant will die; and $9=$ dead plant.

Genetic crosses. Based on results of the mating type-specific PCR assay, isolates of each Ascochyta spp. were assigned to mating type and paired with isolates of opposite mating type following the technique of Trapero-Casas and Kaiser (60) and Wilson and Kaiser (65). Both interspecific and intraspecific crosses were performed with A. rabiei, A. fabae, A. pisi, A. lentis, and A. viciae-villosae. The intraspecific cross of $A$. rabiei mating type tester isolates AR21 (ATCC 76502, MAT1-1) and AR20 (ATCC 76501, MAT1-2) were used as positive controls for all crosses (60). Autoclaved chickpea stem pieces (4 to $6 \mathrm{~cm}$ ) were placed in $15-\mathrm{ml}$ sterile conical centrifuge tubes containing $10 \mathrm{ml}$ of a mixed conidial suspension of MAT1-1 and MAT1-2 isolates $\left(1 \times 10^{6}\right.$ co$\mathrm{nidia} / \mathrm{ml}$ for each isolate) for $1 \mathrm{~h}$ at room temperature $\left(22 \pm 2{ }^{\circ} \mathrm{C}\right)$, after which the liquid was decanted. Stems were placed on 10 layers of autoclaved filter paper moistened with sterile distilled water in 9-cm glass petri plates. Petri plates were incubated in the dark at $20^{\circ} \mathrm{C}$ for $24 \mathrm{~h}$, then incubated continuously in the dark at $10^{\circ} \mathrm{C}$ for 45 days. In order to facilitate ascospore discharge, stem pieces were air dried in a laminar flow hood for $24 \mathrm{~h}$ and stuck to $4-\mathrm{cm}^{2}$ WA blocks attached to the inner surface of petri plate lids that then were placed over the WA plates (65). Ascospores were discharged onto the surface of the WA and incubated for $18 \mathrm{~h}$ to allow germination. Single-ascospore colonies were established by transferring single, germinated ascospores to V8 agar plates with $1-\mathrm{cm}^{2}$ pieces of sterile filter paper. Plates were incubated for 2 weeks at $22^{\circ} \mathrm{C}$ under fluorescent light with a 12 -h photoperiod. For long-term storage, filters were peeled from the plates, dried at room temperature for 7 days, and stored dry at $-20^{\circ} \mathrm{C}$ following the technique described by Peever et al. (48).

Pathogenicity of hybrid ascospore progeny. Parental isolates and 114 ascospore progeny from the cross of $A$. pisi isolate AP1 $\times$ A. fabae isolate AF1 isolates were inoculated as described above on faba bean and pea in the greenhouse to assess pathogenicity. Inoculated and control plants were covered with $600-\mathrm{ml}$ plastic cups for $48 \mathrm{~h}$ and randomized over the greenhouse benches in a completely randomized design. Four replicate pots (one plant per pot) were assigned to each treatment at random and each isolate was inoculated once. Parental isolates and 110 ascospore progeny of the AP1 $\times$ AF 1 cross and parents were inoculated as described above under growth chamber conditions of $18^{\circ} \mathrm{C}$ with $>90 \%$ relative humidity and a 12-h photoperiod under fluorescent light of $\approx 350 \mu \mathrm{mol} / \mathrm{m}^{2} / \mathrm{s}$. Inoculations were arranged in a randomized complete block design with two replicates. Each replicate pot (three to eight plants per pot) was assigned to treatments at random, and inoculated and control plants were covered with 30-by60-cm autoclave bags (Fisher Scientific, Hampton, NH). Each pot was randomized to one of two growth chambers for an initial $48 \mathrm{~h}$ in the dark, then under a 12-h photoperiod thereafter. Growth chamber inoculations were repeated with 27 selected isolates to assess reproducibility of symptoms. Conidial germination rates on WA were assessed independently for each inoculation experiment as previously described. An isolate was considered pathogenic when pycnidia (i.e., asexual reproductive structures) developed in disease lesions.

Recovery of inoculated isolates from asymptomatic plants. To determine whether the Ascochyta spp. used in this study were able to infect nonhost plants, isolations from nonsymptomatic, inoculated tissues were performed. Inoculated fungi included A. lentis, A. fabae, A. vicae-villosae, A. pisi, and progeny from the AP1 $\times$ AF1 cross. Four leaves and two stem sections were selected at random from each of four asymptomatic inoculated plant tissues and surface disinfested in $95 \%$ ethanol for $30 \mathrm{~s}$ and $0.5 \% \mathrm{NaOCl}$ for $60 \mathrm{~s}$, then rinsed twice with sterile distilled water. Tissue pieces were dried on sterile filter paper, plated on WA plates, and incubated at $15^{\circ} \mathrm{C}$ with a 12 -h photoperiod. Isolates were hyphal-tipped onto V8 agar plates, incubated, and stored as described above. Isolates recovered from plant tissues were identified using cultural and morphological characters. A subset of the recovered isolates was re-inoculated on the original hosts.

Amplified fragment length polymorphism markers. Amplified fragment length polymorphism (AFLP) markers were developed to verify the hybrid status of the ascospore progeny and to assess meiotic compatibility among isolates by comparing segregation distortion between intraspecific and interspecific crosses. The AFLP procedure was carried out as described by Vos et al. (64) with the following modifications. Restriction digestion of genomic DNA (400 ng) of parental and hybrid progeny isolates was performed in 40- $\mu$ l volumes containing $1 \times$ restriction buffer, $1 \times$ bovine serum albumen (New England Biolabs), $10 \mathrm{U}$ of EcoRI, and $5 \mathrm{U}$ of $\mathrm{Mse} \mathrm{I}$ (New England Biolabs). Reactions were incubated at $37^{\circ} \mathrm{C}$ overnight. Adapters were ligated by mixing $10 \mu \mathrm{l}$ of restriction digestion reaction with $5 \mu \mathrm{M}$ MseI adaptor, 1× ligase buffer, and $2 \mathrm{U}$ of T4 DNA ligase enzyme (Invitrogen). Restriction-ligation mix was incubated at $37^{\circ} \mathrm{C}$ for $4 \mathrm{~h}$. Adaptorligated DNA was diluted 1:10 in distilled water to serve as template for selective PCR. Selective PCR reactions contained $10 \mu \mathrm{l}$ of the diluted DNA template, $1 \times$ PCR buffer (New England Biolabs), $200 \mu \mathrm{M}$ dNTPs (New England Biolabs), $375 \mathrm{nM}$ each of EcoRI-XX and MseI-XX selective primers, and $1 \mathrm{U}$ of Taq polymerase (New England Biolabs). Peever et al. (51) demonstrated that primer combinations with up to two selective nucleotides per primer generate a number of amplicons for A. rabiei that can be scored easily in silver-stained gels. Reactions were carried out in a My-Cycler thermal cycler (Bio-Rad) under the following cycling conditions: The first amplification cycle consisted of an 
initial extension step at $72^{\circ} \mathrm{C}$ for $1 \mathrm{~min}$; then a denaturation step at $94^{\circ} \mathrm{C}$ for $3 \mathrm{~min}$; followed by nine cycles of $94^{\circ} \mathrm{C}$ for $30 \mathrm{~s}, 65^{\circ} \mathrm{C}$ for $30 \mathrm{~s}$ with a $1^{\circ} \mathrm{C}$ touchdown after each cycle, and $72^{\circ} \mathrm{C}$ for $1 \mathrm{~min}$; then 35 cycles of $94^{\circ} \mathrm{C}$ for $30 \mathrm{~s}, 56^{\circ} \mathrm{C}$ for $30 \mathrm{~s}$, and $72^{\circ} \mathrm{C}$ for $1 \mathrm{~min}$; and the final cycle consisted of a $72^{\circ} \mathrm{C}$ extension for $5 \mathrm{~min}$. Following amplification, $5 \mu \mathrm{l}$ of loading dye (98\% formamide, $10 \mathrm{mM}$ EDTA, $\mathrm{pH} 8.0,0.025 \%$ bromophenol blue, and $0.025 \%$ xylene cyanole) was added to each reaction and the reaction mix denatured for $5 \mathrm{~min}$ at $99^{\circ} \mathrm{C}$, then cooled on ice. Each sample $(4 \mu \mathrm{l})$ was loaded and separated on $4 \%$ denaturing polyacrylamide gels for $\approx 2.5 \mathrm{~h}$ at $100 \mathrm{~W}$ with a $45^{\circ} \mathrm{C}$ temperature limit using a Bio-Rad Sequi-Gen GT DNA Electrophoresis Cell (Bio-Rad). The two parental isolates were loaded in the first two lanes adjacent to the DNA size ladders to serve as controls for the progeny. Gels were silver stained after the method of Bassam et al. (2) and dried overnight before visual scoring of the bands. Gels were digitized using a flatbed document scanner to preserve each gel image.

Data analysis. Putative alleles at each polymorphic AFLP locus and at the mating type locus were scored using a binary code ( 1 and 0$)$ corresponding to positive and null alleles for the AFLP loci and the MAT1-2 and MAT1-1 idiomorphs, respectively. Only AFLP markers that were polymorphic between parental isolates and easily scorable for both parents and progeny were scored. Segregation of mating type and AFLP alleles among progeny isolates was tested using a $\chi^{2}$ test. Segregation ratios were tested against the null hypothesis of 1:1 segregation, which is the expected ratio for the segregation of two alleles at a single locus in a haploid organism (37). Segregation of alleles at each locus was considered significantly distorted at $P<0.05$.

\section{RESULTS}

Host specificity of Ascochyta spp. A. fabae, A. lentis, A. pisi, A. rabiei, and $A$. viciae-villosae only caused disease on their respective hosts, faba bean, lentil, pea, chickpea, and hairy vetch, respectively (Table 2). Water-inoculated control plants remained healthy, with no symptoms. Inoculations of additional plant accessions or varieties for each host species gave similar results (data not shown). Germination rates of conidia were consistently high (80 to $100 \%$ ) and did not vary significantly among isolates or experiments. At 5 to 7 days after inoculation, tan to brown lesions appeared on leaves and stems of host plants when inoculated with their respective pathogens. Typical necrotic lesions with chlorotic halos and concentric rings of pycnidia developed 2 weeks after inoculation. In contrast, Ascochyta isolates failed to produce any visible symptoms when inoculated on their "nonhost" plants (i.e., plant species other than those from which they originally were isolated) and no obvious macroscopic plant responses were observed. Although no disease symptoms were observed on nonhost legumes, A. fabae, A. lentis, A. pisi, A. rabiei, and $A$. viciae-villosae were readily isolated from surface-disinfested tissues of pea and lentil, chickpea and pea, faba bean, pea, and pea and lentil, respectively. Rates of recovery varied among experiments and host plants, but $>50 \%$ of attempted isolations from both leaves and stems were successful. Morphological and cultural characters of the recovered isolates were identical to the inoculated isolates. Recovered isolates were always pathogenic when re-inoculated on their parental hosts (data not shown).

Genetic crosses. Both intraspecific and interspecific crosses were successful among several combinations of strains of opposite mating type (data not shown). Crossing success varied among pairings but no correlation between fertility and width of the cross (i.e., whether the cross was interspecific or intraspecific) or geographic location of parents was observed. No attempt was made to cross A. fabae or A. pisi with either A. lentis or A. viciaevillosae because previous crosses of these species were demonstrated to have significant postzygotic mating defects (28). A. fabae was fully interfertile with $A$. pisi, and $A$. lentis was fully interfertile with A. viciae-villosae. Successful interspecific crosses were made between isolates from distinct geographic areas (e.g., A. fabae isolate AF1 from Canada and A. pisi isolate AP1 from Bulgaria). All ascospore progeny recovered from interspecific crosses were viable, and morphological and cultural characters (pycnidial color, conidia size and shape, and septal number) of the progeny ranged from those typical of the parental types, to intermediate, to more nonparental types. Intraspecific pairings between A. fabae, A. pisi, and A. viciae-villosae isolates of opposing mating type also were consistently successful. Colony morphology and growth rates of the intraspecific progeny generally were less variable than those of comparable interspecific crosses. Crosses between A. rabiei mating type tester isolates AR21 and AR20 were consistent and produced large numbers of ascospores.

Pathogenicity of progeny from an $A$. pisi $\times$ A. fabae. In all, 114 ascospore progeny from the cross of $A$. pisi isolate AP1 and A. fabae isolate AF1, and the parental isolates, AF1 and AP1, were inoculated simultaneously to faba bean and pea in the greenhouse (Table 3; Fig. 1). Conidial germination rates on WA of both parental and progeny isolates ranged from 70 to $100 \%$. Typical disease symptoms, including necrotic tan lesions with concentric rings of pycnidia, developed when each parental isolate was inoculated on its respective host. Mean disease ratings of the AP1 and AF1 parents were 6 on pea and 4 on faba bean, respectively. Disease ratings of parental isolates were consistent among replicates, and independent inoculation assays also were consistently higher than those induced by progeny isolates (data not shown). Thirty progeny isolates were pathogenic on pea in the greenhouse, producing lesions with pycnidia (Table 3 ). Lesions were small, few, and scattered relative to lesions produced by parental isolate AP1 and tended to develop at the leaf margins and on a few leaflets or single leaves per plant. Stem lesions resulting from inoculation with AP1 developed pycnidia, but stem lesions produced by progeny isolates never sporulated. Few isolates were consistently pathogenic on all replicate plants and the majority were pathogenic on only a single replicate. Only four progeny isolates (C7-11, -15, -67, and -84) were pathogenic on faba bean, and caused single lesions with scattered pycnidia on single leaves on up to two replicates. Faba beans inoculated with isolate AF1 developed many leaf and stem lesions with pycnidia that became larger and necrotic after 2 weeks. Progeny isolates that were pathogenic to pea were not pathogenic to faba bean and vice versa. The remainder of the progeny isolates incited a hypersensitive-like response (data not shown) on a single host or both hosts, but the degree of the reaction was different between hosts and

TABLE 2. Pathogenicity of five Ascochyta spp. on five legume hosts

\begin{tabular}{|c|c|c|c|c|c|c|}
\hline \multirow[b]{2}{*}{ Fungal species } & \multirow[b]{2}{*}{ Isolate code } & \multicolumn{5}{|c|}{ Host $^{\mathrm{a}}$} \\
\hline & & Chickpea & Faba bean & Lentil & Pea & Hairy vetch \\
\hline Ascochyta rabiei & AR735 & 7.8 & 0 & 0 & 0 & 0 \\
\hline A. fabae & $\mathrm{AF} 1$ & 0 & 4.8 & 0 & 0 & 0 \\
\hline A. pisi & AP1 & 0 & 0 & 0 & 5.8 & 0 \\
\hline A. viciae-villosae & AV22 & 0 & 0 & 0 & 0 & 2.5 \\
\hline
\end{tabular}

${ }^{a}$ Mean disease severity (eight replicate pots) assessed using a modified 0-to-9 rating scale developed for A. rabiei (8). 
among replicates. Pea plants displayed a mild hypersensitive-like reaction that included tan flecks on the upper leaves and stems, and some stem girdling and leaf shriveling. In contrast, faba bean plants showed flecks of hypersensitive-like reaction, on both upper and lower leaves and stems, that resembled reddish-brown spots.

In all, 110 ascospore progeny and the AF1 and AP1 parents were used to inoculate faba bean and pea in growth chambers (Ta-

TABLE 3. Pathogenicity of progeny from cross of Ascochyta pisi isolate AP1 by Ascochyta fabae isolate AF1 to faba bean and pea under greenhouse conditions $^{\mathrm{a}}$

\begin{tabular}{|c|c|c|c|c|c|}
\hline Isolate $^{b}$ & Faba bean & Pea & Isolate $^{b}$ & Faba bean & Pea \\
\hline AF1 & 4 & 0 & C7-61 & 0 & 0 \\
\hline$A P 1$ & 0 & 4 & $C 7-62$ & 0 & 3 \\
\hline C7-1 & 0 & 0 & $C 7-63$ & 0 & 1 \\
\hline C7-2 & 0 & 0 & C7-64 & 0 & 0 \\
\hline C7-3 & 0 & 0 & C7-65 & 0 & 2 \\
\hline C7-4 & 0 & 0 & C7-66 & 0 & 1 \\
\hline C7-5 & 0 & 0 & C7-67 & 2 & 0 \\
\hline C7-6 & 0 & 0 & C7-68 & 0 & 1 \\
\hline C7-7 & 0 & 0 & C7-69 & 0 & 0 \\
\hline C7-8 & 0 & 0 & $C 7-70$ & 0 & 3 \\
\hline C7-9 & 0 & 0 & C7-71 & 0 & 0 \\
\hline C7-10 & 0 & 0 & C7-72 & 0 & 0 \\
\hline C7-11 & 1 & 0 & $C 7-73$ & 0 & 1 \\
\hline C7-12 & 0 & 1 & C7-74 & 0 & 0 \\
\hline C7-13 & 0 & 0 & $C 7-75$ & 0 & 1 \\
\hline C7-14 & 0 & 0 & $C 7-76$ & 0 & 1 \\
\hline C7-15 & 1 & o & $C 7-77$ & 0 & 1 \\
\hline C7-16 & 0 & 0 & C7-78 & 0 & 0 \\
\hline C7-17 & 0 & 1 & C7-79 & 0 & 0 \\
\hline C7-18 & 0 & 0 & $C 7-80$ & 0 & 2 \\
\hline C7-19 & 0 & 0 & $C 7-81$ & 0 & 1 \\
\hline C7-20 & 0 & 0 & $C 7-82$ & 0 & 3 \\
\hline$C 7-21$ & 0 & 4 & C7-83 & 0 & 0 \\
\hline C7-22 & 0 & 0 & C7-84 & 1 & 0 \\
\hline C7-23 & 0 & 1 & $C 7-85$ & 0 & 4 \\
\hline C7-24 & 0 & 4 & C7-86 & 0 & 0 \\
\hline C7-25 & 0 & 1 & C7-87 & 0 & 0 \\
\hline C7-27 & 0 & 0 & C7-88 & 0 & 4 \\
\hline C7-28 & 0 & 0 & C7-89 & 0 & 4 \\
\hline C7-29 & 0 & 0 & C7-90 & 0 & 0 \\
\hline C7-30 & 0 & 2 & C7-91 & 0 & 0 \\
\hline C7-31 & 0 & 1 & C7-92 & 0 & 0 \\
\hline C7-32 & 0 & 0 & C7-93 & 0 & 0 \\
\hline C7-33 & 0 & 1 & C7-94 & 0 & 0 \\
\hline C7-34 & 0 & 0 & C7-95 & 0 & 0 \\
\hline C7-35 & 0 & 0 & C7-96 & 0 & 0 \\
\hline C7-36 & 0 & 0 & C7-97 & 0 & 1 \\
\hline C7-37 & 0 & 0 & C7-98 & 0 & 3 \\
\hline C7-39 & 0 & 1 & C7-100 & 0 & 0 \\
\hline C7-40 & 0 & 1 & C7-101 & 0 & 0 \\
\hline C7-41 & 0 & 0 & C7-102 & 0 & 0 \\
\hline C7-42 & 0 & 0 & C7-103 & 0 & 0 \\
\hline C7-43 & 0 & 0 & C7-104 & 0 & 1 \\
\hline C7-44 & 0 & 0 & C7-105 & 0 & 0 \\
\hline C7-45 & 0 & 0 & C7-106 & 0 & 0 \\
\hline C7-46 & 0 & 0 & C7-107 & 0 & 0 \\
\hline C7-48 & 0 & 0 & C7-108 & 0 & 0 \\
\hline C7-49 & 0 & 0 & C7-109 & 0 & 0 \\
\hline C7-50 & 0 & 0 & C7-110 & 0 & 0 \\
\hline C7-51 & 0 & 0 & C7-111 & 0 & 0 \\
\hline C7-52 & 0 & 0 & C7-112 & 0 & 0 \\
\hline C7-53 & 0 & 0 & C7-113 & 0 & 0 \\
\hline C7-54 & 0 & 0 & C7-114 & 0 & 0 \\
\hline C7-55 & 0 & 0 & C7-116 & 0 & 0 \\
\hline C7-56 & 0 & 0 & C7-117 & 0 & 0 \\
\hline C7-58 & 0 & 0 & C7-118 & 0 & 0 \\
\hline C7-59 & 0 & 0 & C7-119 & 0 & 0 \\
\hline C7-60 & 0 & 0 & C7-120 & 0 & 0 \\
\hline
\end{tabular}

a Number of plants displaying disease symptoms out of four inoculated plants 2 weeks after inoculation. Isolates in bold were pathogenic on faba bean and those in italics were pathogenic on pea.

${ }^{\mathrm{b}}$ Isolate inoculated. AF1 and AP1 are parental isolates and C7-XX isolates are progeny isolates from the $\mathrm{AP} 1 \times \mathrm{AF} 1$ cross. ble 4; Fig. 1). Conidial germination rates of both parental and progeny isolates were similar to those mentioned above (data not shown). Typical disease symptoms, including necrotic tan lesions with pycnidia, developed when each parental isolate was inoculated on its respective host, with mean disease ratings of 7 on faba bean and 5 on pea. Disease ratings of parental isolates were consistently high among replicates and inoculation assays and were consistently higher than those induced by progeny isolates (data not shown). Only 15 of 110 progeny isolates were pathogenic to pea in the first round of inoculations in the growth chambers, resulting in small leaf lesions with few pycnidia (Table 4). Of 30 isolates that were pathogenic to pea in the greenhouse, 9 also were pathogenic to pea under growth chamber conditions (C7-23, -24, -31, -33, -39, -40, -65, -70, and -98). In addition, two isolates (C7-59 and -60$)$ that were not pathogenic to pea and two isolates that were pathogenic to faba bean only (C7-67 and -84) in the greenhouse were pathogenic only on pea in the growth chambers. Isolates incited lesions on a maximum of two plants per pot. No progeny isolates were pathogenic to faba bean plants under growth chamber conditions. Isolates incited a hypersensitive-like response on both hosts or on a single host alone, and the degree of severity of the reaction was different among plants in the same pot. At $48 \mathrm{~h}$ after inoculation, microscopic observations of faba bean and pea leaves inoculated with either parental or progeny isolates showed that these fungi formed appressoria on both host and nonhost legumes leaves (data not shown). When nonhost plants were inoculated with the parental isolates, they exhibited no obvious resistance reactions. Parental and progeny isolates were recovered frequently ( $>80 \%$ ) from inoculated asymptomatic tissues of nonhost plants. To test the reproducibility of symptoms among experiments, 27 isolates, including those causing sporulating lesions, were retested (Fig. 1). Only two isolates, C7-33 and -65 , consistently caused lesions on pea under both greenhouse and growth chamber conditions.

Molecular marker segregation. Segregation of mating type and AFLP markers was used to assess the hybrid status of the progeny and to measure segregation distortion in intraspecific and interspecific crosses. A MAT1-2-specific product was amplified from 20 of $36(56 \%), 11$ of 28 (39\%), 30 of $53(57 \%), 30$ of 56 $(54 \%)$, and 31 of $58(53 \%)$ progeny isolates from the $\mathrm{AF} 1 \times \mathrm{AF} 3$, $\mathrm{AF} 3 \times \mathrm{AP} 4, \mathrm{AP} 1 \times \mathrm{AP} 2, \mathrm{AP} 1 \times \mathrm{AF} 1$, and AL1 $\times$ AV22 crosses, respectively (Table 5 ). The null hypothesis of a $1: 1$ segregation ratio of mating type could not be rejected for any of the crosses (Table 5). Segregation of AFLP markers confirmed the hybrid status of progeny from the AF1 $\times \mathrm{AF} 3, \mathrm{AP} 1 \times \mathrm{AP} 2, \mathrm{AP} 1 \times \mathrm{AF} 1$, and AL1 $\times$ AV22 crosses with 16 of $16(100 \%), 12$ of $14(86 \%)$, 25 of $29(86 \%)$, and 24 of 26 (92\%) AFLP markers, respectively, segregating in 1:1 fashion (Table 6). A Student's $t$ test for a hypothesized $0 \%$ difference in markers segregating in a 1:1 fashion between interspecific crosses and intraspecific crosses could not be rejected $(P=0.90)$.

\section{DISCUSSION}

Artificial inoculations demonstrated that legume-associated Ascochyta fungi caused disease only on the hosts from which they originally were isolated. These results agree with previous studies, where inoculations with isolates of the chickpea pathogen, A. rabiei, failed to cause disease on lentil, pea, and vetch $(24,26$, 30,61). Similarly A. fabae and A. lentis also have been shown to be host-specific (28). We also have demonstrated that closely related Ascochyta spp., previously identified through phylogenetic analyses (49), were interfertile, with no obvious intrinsic mating barriers. Interspecific hybridization of $A$. pisi $\times A$. fabae and A. viciae-villosae $\times A$. lentis was confirmed by the segregation of molecular markers, and these crosses produced viable ascospore progeny. However, artificial inoculations of progeny isolates from the $A$. pisi $\times$ A. fabae cross demonstrated that very few progeny 
were able to induce disease on either parental host. These data suggest that host specificity may be an important premating, extrinsic mating barrier as well as a postmating, intrinsic mating barrier controlling the speciation of these fungi. Mechanisms of speciation of fungi are poorly understood (31); however, host specificity may play an important role in facilitating the speciation of Ascochyta spp. and other host-specific, plant-pathogenic fungi $(14,31)$. It is likely that host specialization acts as a prezygotic isolating mechanism in other plant pathogens, including Phytophthora spp. $(15,16)$, formae speciales of Blumeria graminis $(20,21)$ and Puccinia graminis (22). Our results, together with those of Kaiser et al. (28), where A. rabiei failed to mate with either A. fabae or A. lentis, but A. fabae did mate with A. lentis, demonstrate a strong correlation between phylogenetic distance and the success rate of crosses and putative fitness of hybrid progeny. Phylogenetic analyses using DNA sequence data from multiple regions of the genome have revealed that $A$. rabiei is distantly related to Ascochyta spp. on other legumes and that A. fabae, A. lentis, A. pisi, and A. viciae-villosae all are closely related sister taxa (T. L. Peever, unpublished data).

Segregation ratios of AFLP markers in the progeny of the interspecific crosses AP1 $\times$ AF1 and AL1 $\times$ AV22 were not significantly more skewed than those of intraspecific crosses and indicate a lack of obvious intrinsic postzygotic fertility barriers between these taxa. Distortion of molecular markers at various levels has been reported in wide crosses of some fungi, including Tilletia, Uromyces, Colletotrichum, and Gibberella (11,23,34, 35,53). Distortion of markers in Tilletia and Uromyces spp. was suggested to have resulted from large genetic differences between parents $(35,53)$. Although crosses were fully sexually compatible, progeny isolates were less fit (i.e., less virulent on parental hosts), indicating the existence of extrinsic postzygotic isolating barriers, and the authors speculated that these fungi were in the initial stages of speciation $(34,35,53)$. A genetic map of a cross between genetically distinct lineages of Gibberella zeae revealed high levels of segregation distortion of AFLP markers, segregation bias towards one or the other parent, and recombination suppression among markers on some linkage groups (23). However, no assays were performed to determine the possible effects of such genetic abnormalities on pathogenicity and fitness of the progeny. Pringle and Taylor (54) regard fungal fitness as "the survival and reproductive success of an allele, individual or group." Pathogenicity, which is presumably a heritable trait and under selection in Ascochyta spp. can be considered to be an important fitness parameter for fungi spending a large portion of their life cycle on specific host plants. Kohn (31) has suggested that decreased hybrid fitness may be an important mechanism of fungal speciation for some fungal plant pathogens, and it is possible that this is an important speciation mechanism in legume-associated Ascochyta fungi.
Hybridization between species of fungi and between species of Stramenopiles in nature is thought to be rare, and only a few welldocumented examples exist $(5,31,56)$. Recently, laboratory crosses and more powerful molecular genetic markers have been brought to bear on this question, and results suggest that hybridization between plant pathogens could be occurring more commonly than originally thought. Interfertility tests are a powerful approach to identify closely related taxa and measure the potential for gene flow and recombination between them $(15,16)$. Progeny of interspecific crosses of Ascochyta isolates exhibited a range of morphological variation that was within the range seen for the progeny of intraspecific crosses. The fertility of the parents and germination rate of interspecific progeny appeared to be normal as judged by comparison with intraspecific crosses. Segregation analysis of an intraspecific cross of $A$. rabiei demonstrated 1:1 Mendelian segregation ratios $(P>0.01)$ for five of six microsatellite markers (51). Similarly, segregation analysis of molecular markers in intraspecific crosses of plant-pathogenic ascomycetes, including Tapesia yallundae, Cochliobolus sativus, C. heterostrophus, and B. graminis, have revealed that 84 to $96 \%$ of markers segregated in Mendelian fashion $(12,45,62,66)$. This level of marker distortion is in the same range that we observed among progeny of the interspecific crosses reported here.

Fungal hybridization has potentially important practical consequences because the resulting hybrids may become "superpathogens," combining characteristics of both parents or developing novel host specificities $(38,56)$. Two independent intraspecific crosses between host-specific forms of Colletotrichum gloeosporioides resulted in progeny with varying virulence to both parental hosts, including progeny pathogenic to a single parental host $(10,11)$. When progeny isolates of the $A$. pisi $\times A$. fabae cross were inoculated to both parental hosts under greenhouse and growth chamber conditions, almost all progeny were nonpathogenic to either parental host. The only two progeny isolates that were consistently pathogenic to pea under both greenhouse and growth chamber conditions were much less virulent than the parental isolates (i.e., small and fewer lesions). These observations corroborate results of several other studies where hybrid progeny of crosses of plant-pathogenic fungi were less virulent relative to their parents $(9,15,22,53)$.

We initially suspected that our lack of success in inducing disease with the majority of progeny isolates and the variability among replicates was due to unfavorable environmental conditions for disease in the greenhouse. We attempted to control environmental variables more carefully by moving inoculation experiments into growth chambers; however, results were similar. These data suggest that environmental conditions did not play a major role in the failure of progeny isolates to cause disease on either host. This also is supported by the consistently high disease ratings that resulted from inoculation of the parental isolates, AF1
A

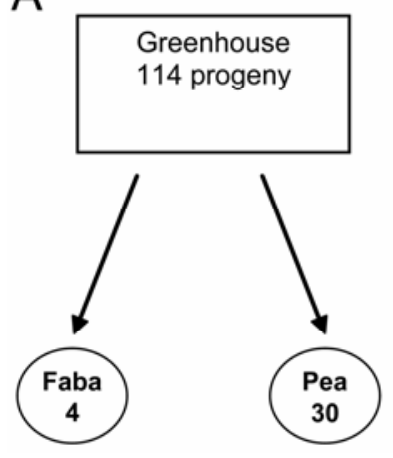

B

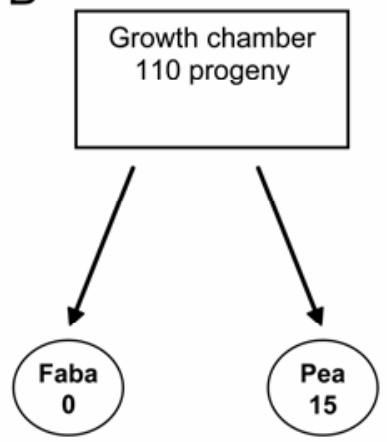

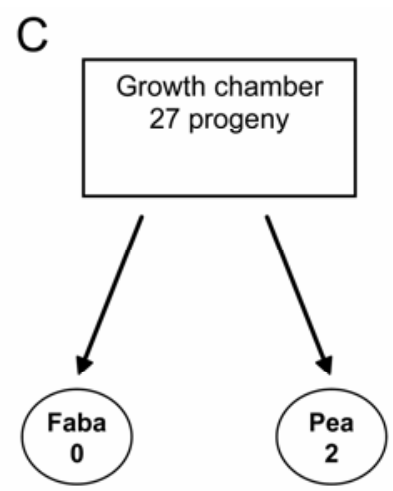

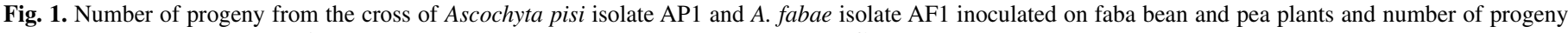

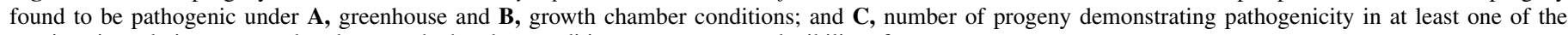
previous inoculations, retested under growth chamber conditions to assess reproducibility of symptoms. 
TABLE 4. Pathogenicity of progeny from cross of Ascochyta pisi isolate AP1 by $A$. fabae isolate AF1 to faba bean and pea under growth chamber conditions $^{\mathrm{a}}$

\begin{tabular}{|c|c|c|c|c|c|}
\hline Isolate $^{b}$ & Faba bean & Pea & Isolate $^{b}$ & Faba bean & Pea \\
\hline $\mathrm{AF} 1 *$ & $11 / 11$ & $14 / 0$ & $C 7-57$ & $11 / 0$ & $13 / 1$ \\
\hline$A P 1 *$ & $14 / 0$ & $14 / 14$ & C7-58 & $12 / 0$ & $14 / 0$ \\
\hline C7-1 & $12 / 0$ & $12 / 0$ & C7-59 & $13 / 0$ & $11 / 2$ \\
\hline C7-2 & $11 / 0$ & $14 / 0$ & $C 7-60$ & $12 / 0$ & $14 / 14$ \\
\hline C7-3 & $10 / 0$ & $14 / 0$ & C7-61 & $11 / 0$ & $13 / 0$ \\
\hline C7-4 & $12 / 0$ & $12 / 0$ & C7-62* & nt & $16 / 0$ \\
\hline C7-5 & $12 / 0$ & $13 / 0$ & C7-63 & $12 / 0$ & $14 / 0$ \\
\hline C7-6 & $11 / 0$ & $12 / 0$ & C7-64 & $12 / 0$ & $12 / 0$ \\
\hline C7-7 & $11 / 0$ & $10 / 0$ & $C 7-65 *$ & $12 / 0$ & $22 / 9$ \\
\hline C7-8 & $12 / 0$ & $11 / 0$ & C7-66* & $12 / 0$ & $9 / 0$ \\
\hline C7-9 & $12 / 0$ & $13 / 0$ & C7-67* & $12 / 0$ & $7 / 1$ \\
\hline C7-10 & $11 / 0$ & $14 / 0$ & C7-68* & $12 / 0$ & $6 / 0$ \\
\hline C $7-11 *$ & $11 / 0$ & $12 / 0$ & $\mathrm{C} 7-69 *$ & $12 / 0$ & $7 / 0$ \\
\hline C $7-12^{*}$ & $11 / 0$ & $11 / 0$ & $C 7-70^{*}$ & $6 / 0$ & $12 / 3$ \\
\hline C7-13 & $12 / 0$ & $14 / 0$ & C7-71 & $11 / 0$ & $15 / 0$ \\
\hline C7-14 & $12 / 0$ & $11 / 0$ & C7-72 & $n t$ & $14 / 2$ \\
\hline C7-15 & $10 / 0$ & $10 / 0$ & C7-73* & $12 / / 0$ & $7 / 0$ \\
\hline C7-16 & $9 / 0$ & $9 / 0$ & C $7-75^{*}$ & $12 / 0$ & $12 / 0$ \\
\hline C7-17 & $9 / 0$ & $11 / 0$ & C7-76* & $10 / 0$ & $11 / 0$ \\
\hline C7-18 & $11 / 0$ & $13 / 0$ & C7-77* & $11 / 0$ & $10 / 0$ \\
\hline C7-19 & $12 / 0$ & $10 / 0$ & C7-78 & $12 / 0$ & $16 / 0$ \\
\hline C7-20 & $11 / 0$ & $14 / 0$ & C7-79 & $12 / 0$ & $16 / 0$ \\
\hline C $7-21 *$ & $12 / 0$ & $8 / 0$ & C7-80* & $11 / 0$ & $10 / 0$ \\
\hline C7-22 & $12 / 0$ & $14 / 0$ & C7-81* & $11 / 0$ & $5 / 0$ \\
\hline$C 7-23 *$ & $12 / 0$ & $8 / 1$ & C7-82* & $12 / 0$ & $10 / 0$ \\
\hline$C 7-24 *$ & $11 / 0$ & $9 / 3$ & C7-84* & $11 / 0$ & $10 / 1$ \\
\hline C7-25* & $12 / 0$ & $7 / 0$ & C7-85 & $11 / 0$ & $14 / 0$ \\
\hline C7-26 & $12 / 0$ & $11 / 0$ & C7-89 & $11 / 0$ & $15 / 0$ \\
\hline C7-27 & $12 / 0$ & $12 / 0$ & C7-90 & $12 / 0$ & $15 / 0$ \\
\hline C7-28 & $11 / 0$ & $13 / 0$ & C7-91 & $12 / 0$ & $15 / 0$ \\
\hline C7-29 & $11 / 0$ & $13 / 0$ & C7-92 & $12 / 0$ & $14 / 0$ \\
\hline C7-30* & $11 / 0$ & $9 / 0$ & C7-93 & $12 / 0$ & $15 / 0$ \\
\hline$C 7-31 *$ & $12 / 0$ & $7 / 1$ & C7-94 & $12 / 0$ & $15 / 0$ \\
\hline C7-32 & $12 / 0$ & $9 / 0$ & C7-95 & $12 / 0$ & $14 / 0$ \\
\hline$C 7-33 *$ & $11 / 0$ & $23 / 4$ & C7-96 & $12 / 0$ & $14 / 0$ \\
\hline C7-34* & $12 / 0$ & $13 / 0$ & C7-97 & $10 / 0$ & $15 / 0$ \\
\hline C7-35 & $11 / 0$ & $13 / 0$ & C7-98 & $12 / 0$ & $15 / 12$ \\
\hline C7-36 & $11 / 0$ & $13 / 0$ & C7-101 & $12 / 0$ & $15 / 0$ \\
\hline C7-37 & $11 / 0$ & $11 / 0$ & C7-102 & $12 / 0$ & $14 / 0$ \\
\hline$C 7-39 *$ & $12 / 0$ & $6 / 1$ & C7-103 & $11 / 0$ & $14 / 0$ \\
\hline$C 7-40 *$ & $10 / 0$ & $6 / 1$ & C7-104 & $12 / 0$ & $\mathrm{nt}$ \\
\hline C7-41 & $10 / 0$ & $12 / 0$ & C7-105 & $11 / 0$ & $14 / 0$ \\
\hline C7-42 & $12 / 0$ & $15 / 0$ & C7-107 & $12 / 0$ & $14 / 0$ \\
\hline C7-43 & $12 / 0$ & $15 / 0$ & C7-108 & $12 / 0$ & $14 / 0$ \\
\hline C7-44 & $13 / 0$ & $16 / 0$ & C7-109 & $12 / 0$ & $14 / 0$ \\
\hline C $7-45$ & $14 / 0$ & $14 / 0$ & C7-110 & $12 / 0$ & $14 / 0$ \\
\hline C7-46 & $13 / 0$ & $15 / 0$ & C7-111 & $12 / 0$ & $14 / 0$ \\
\hline C7-47 & $12 / 0$ & $15 / 0$ & C7-112 & $12 / 0$ & $14 / 0$ \\
\hline C7-48 & $13 / 0$ & $16 / 0$ & C7-113 & $12 / 0$ & $14 / 0$ \\
\hline C7-49 & $12 / 0$ & $15 / 0$ & C7-114 & $12 / 0$ & $14 / 0$ \\
\hline C7-50 & $12 / 0$ & $15 / 0$ & C7-115 & $12 / 0$ & $16 / 0$ \\
\hline C7-51 & $12 / 0$ & $14 / 0$ & C7-116 & $12 / 0$ & $14 / 0$ \\
\hline C7-53 & $13 / 0$ & $14 / 0$ & C7-117 & $12 / 0$ & $15 / 0$ \\
\hline C7-54 & $12 / 0$ & $14 / 0$ & C7-118 & $12 / 0$ & $14 / 0$ \\
\hline C7-55 & $11 / 0$ & $13 / 0$ & C7-119 & $12 / 0$ & $14 / 0$ \\
\hline C7-56 & $13 / 0$ & $13 / 0$ & C7-120 & $12 / 0$ & $15 / 0$ \\
\hline
\end{tabular}

a Number of inoculated plants/number of plants displaying disease symptoms. Isolates in italics were pathogenic on pea; nt $=$ not tested. Twenty-seven isolates, indicated by asterisk $(*)$, were re-inoculated under growth chamber conditions in a separate experiment to confirm pathogenicity. Only isolates C7-33 and C7-65 displayed pathogenicity on pea in 1 of 14 and 7 of 13 plants, respectively.

${ }^{\mathrm{b}}$ Isolate inoculated. AF1 and AP1 are parental isolates and C7-XX isolates are progeny isolates from the $\mathrm{AP} 1 \times \mathrm{AF} 1$ cross.

and AP1, in either the greenhouse or growth chambers. Last, it is likely that the faba bean and pea germ plasm used in this study was not genetically uniform and may have been segregating at resistance loci. This may explain the inconsistent results of progeny inoculations, particularly on faba bean, which is a cross-pollinated plant. Future inoculation experiments with interspecific and intraspecific hybrids of Ascochyta spp. need to be performed with
TABLE 5. Segregation of mating type among progeny of intraspecific and interspecific crosses of Ascochyta spp.

\begin{tabular}{lccccc}
\hline Comparison, cross & $N^{\mathrm{a}}$ & $M A T 1-1^{\mathrm{b}}$ & $M A T 1-2^{\mathrm{c}}$ & $\chi^{2}$ & $P^{\mathrm{d}}$ \\
\hline Intraspecific & & & & & \\
AF1 $\times$ AF3 & 36 & 16 & 20 & 0.44 & 0.51 \\
AP1 $\times$ AP2 & 53 & 23 & 30 & 0.92 & 0.34 \\
Interspecific & & & & & \\
AP1 $\times$ AF1 & 56 & 26 & 30 & 0.29 & 0.59 \\
AF3 $\times$ AP4 & 28 & 17 & 11 & 1.29 & 0.26 \\
AL1 $\times$ AV22 & 58 & 27 & 31 & 0.28 & 0.60 \\
\hline
\end{tabular}

a Number of progeny isolates analyzed.

b MAT1-1 isolates identified using $\alpha$ box-specific primers; progeny from AF3 $\times$ AP4 cross were screened only against high-mobility-group region (HMG) box-specific primers.

c MAT1-2 isolates identified using HMG box-specific primers.

${ }^{\mathrm{d}} P=$ probability of a larger chi-square value under the null hypothesis of a 1:1 ratio.

genetically uniform host plants generated specifically for these types of pathogenicity assays.

The genetics of host species specificity in fungi is poorly understood; however, genetic and molecular analyses of crosses between host-specific isolates of Magnaporthe grisea have allowed the identification and cloning of genetic loci ( $P W L$ genes) involved in host specificity $(29,57)$. $P W L$ genes appear to operate similarly to classical avirulence genes governing cultivar specificity (57). Our segregation ratios were highly skewed towards avirulence among progeny of interspecific hybrids and symptoms were not consistent among replicates in our assay system; therefore, we were unable to determine the genetic control of pathogenicity to either host. However, our data strongly suggest that the genetic control of specificity on each host is not controlled by a single genetic locus, and the reduction of virulence of the progeny relative to the parents also supports a quantitative genetic model for the control of virulence. Genetic analyses of crosses between $M$. grisea pathogenic to weeping lovegrass and pathogenic to rice suggested that progeny causing limited lesions on rice were due to either the action of a major avirulence gene or the cumulative effects of minor genes determining lesion size (63). It is likely that recombination among certain regions of the parental genomes, which are required for pathogenicity on each host, causes the hybrids to be less fit on each host, a process that has been referred to as "genetic disharmony" $(3,35)$. The breakdown of linkage disequilibrium or epistatic interactions among loci controlling host specificity could be involved in the highly skewed pathogenicity ratios observed among progeny of interspecific crosses of Ascochyta spp. Hiura (21) suggested that, because host specificity genes in each forma speciales of Erysiphe graminis (=B. graminis) are linked, hybridization between forma speciales results in the loss of sets of pathogenicity alleles from the original complement, resulting in hybrid progeny that are less aggressive to either parental host. We speculate that suites of alleles at multiple genetic loci have evolved in legume-associated Ascochyta spp. that allow each form to induce disease on a specific host and not on others $(3,33)$. Hybrids of $E$. graminis $\mathrm{f}$. sp. tritici $\times E$. graminis f. sp. agropyri, pathogenic to parental hosts wheat and wheatgrass, have reduced survival in greenhouse experiments (21). When wide-host-range progeny were grown in a mixture on wheat for several generations, progeny infecting wheatgrass gradually were replaced by progeny infecting wheat. The same effect was observed when the wide-host-range progeny mixture was grown on wheatgrass where progeny infecting wheatgrass became dominant (21). It is likely that host specificity provides a strong prezygotic isolating mechanism in Ascochyta which would limit opportunities for hybridization. If rare hybrids are formed, host specificity also might provide a postzygotic isolating barrier if progeny have low fitness on plants and are unable to compete with parental isolates or adapt to other ecological niches. 
TABLE 6. Segregation of amplified fragment length polymorphism markers among progeny of intraspecific and interspecific crosses of Ascochyta spp.

\begin{tabular}{|c|c|c|c|c|c|}
\hline Comparison, $\operatorname{cross}^{\mathrm{a}}$ & EcoRI adapter ${ }^{\mathrm{b}}$ & MseI adapter ${ }^{\mathrm{c}}$ & Polymorphic markers & Markers segregating $1: 1^{\mathrm{d}}$ & Distorted $(\%)^{\mathrm{e}}$ \\
\hline \multicolumn{6}{|l|}{ Intraspecific } \\
\hline \multirow[t]{6}{*}{$\mathrm{AF} 1 \times \mathrm{AF} 3$} & $\mathrm{TT}$ & $\mathrm{AG}$ & 8 & 8 & 0 \\
\hline & $\mathrm{TC}$ & $\mathrm{AG}$ & 1 & 1 & 0 \\
\hline & TG & AA & 1 & 1 & 0 \\
\hline & TA & $\mathrm{AG}$ & 2 & 2 & 0 \\
\hline & $\mathrm{TT}$ & $\mathrm{AC}$ & 2 & 2 & 0 \\
\hline & $\mathrm{C}$ & AA & 2 & 2 & 0 \\
\hline Total & $\ldots$ & $\ldots$ & 16 & 16 & 0 \\
\hline \multirow[t]{5}{*}{$\mathrm{AP} 1 \times \mathrm{AP} 2$} & TT & $\mathrm{AG}$ & 5 & 5 & 0 \\
\hline & $\mathrm{TC}$ & $\mathrm{AG}$ & 3 & 3 & 0 \\
\hline & TA & $\mathrm{AG}$ & 4 & 3 & 25 \\
\hline & TG & $\mathrm{AG}$ & 1 & 1 & 0 \\
\hline & A & $\mathrm{AC}$ & 1 & 0 & 100 \\
\hline Total & $\ldots$ & $\ldots$ & 14 & 12 & 14 \\
\hline \multicolumn{6}{|l|}{ Interspecific } \\
\hline \multirow[t]{3}{*}{$\mathrm{AP} 1 \times \mathrm{AF} 1$} & TT & $\mathrm{AG}$ & 7 & 5 & 29 \\
\hline & $\mathrm{TC}$ & $\mathrm{AG}$ & 10 & 9 & 10 \\
\hline & TG & AT & 12 & 11 & 8 \\
\hline Total & $\ldots$ & $\ldots$ & 29 & 25 & 14 \\
\hline \multirow[t]{3}{*}{$\mathrm{AL} 1 \times \mathrm{AV} 22$} & TT & $\mathrm{AG}$ & 3 & 3 & 0 \\
\hline & $\mathrm{TC}$ & $\mathrm{AG}$ & 16 & 14 & 12 \\
\hline & TG & $\mathrm{AT}$ & 7 & 7 & 0 \\
\hline Total & $\ldots$ & $\ldots$ & 26 & 24 & 8 \\
\hline Total interspecific & $\ldots$ & $\ldots$ & 55 & 49 & 11 \\
\hline Total intraspecific & $\ldots$ & $\ldots$ & 30 & 28 & 7 \\
\hline
\end{tabular}

In the present study, nonhost legumes showed no visible symptoms of disease when inoculated with Ascochyta fungi from other hosts, but Ascochyta fungi were recovered from these inoculated plants. A. rabiei previously was isolated from asymptomatic volunteer pea, lentil, and other legumes growing in a field previously cropped to chickpea (25). Kaiser $(25,26)$ and Khan et al. (30) isolated A. rabiei from surface-disinfested tissue of lentil, pea, alfalfa, wheat, and several weeds, and all isolates were pathogenic to chickpea. The colonization of nonhosts could be of epidemiological importance where other legumes and wheat are used in crop rotations to break the Ascochyta disease cycle. More detailed microscopic analyses of the histology of infection with inoculated nonhost plants needs to be performed to determine the capacity of Ascochyta fungi to infect nonhost legumes. This study has demonstrated the potential for using morphologically similar, host-specific, interfertile, closely related taxa to study the genetic and ecological mechanisms of host specialization and fungal speciation in plant-pathogenic fungi. This is a poorly understood area of plant pathology and our knowledge of the genetics of host specificity at the species level is still remarkably incomplete. This study also has demonstrated the usefulness of combining genetic crosses, molecular markers, and assays of pathogen fitness (i.e., pathogenicity) in addition to phylogenetic studies to help delimit species and understand the process of speciation in plant pathogenic fungi.

\section{LITERATURE CITED}

1. Barve, M. P., Arie, T., Salimath, S. S., Muehlbauer, F. J., and Peever, T. L. 2003. Cloning and characterization of the mating type (MAT) locus from Ascochyta rabiei (teleomorph: Didymella rabiei) and a MAT phylogeny of legume-associated Ascochyta spp. Fungal Genet. Biol. 39:151-167.

2. Bassam, B. J., Caetano-Anolles, G., and Gresshoff, P. M. 1991. Fast and sensitive silver staining of DNA in polyacrylamide gels. Ann. Biochem. 196:80-83.

3. Brasier, C. M. 1987. The dynamics of fungal speciation. Pages 231-260 in: Evolutionary Biology of the Fungi. A. D. M. Rayner, C. M. Brasier, and D. Moore, eds. Cambridge University Press, Cambridge.
4. Brasier, C. M. 2000. The rise of the hybrid fungi. Nature 405:134-135.

5. Brasier, C. M. 2001. Rapid evolution of introduced plant pathogen via interspecific hybridization. BioScience 51:123-133.

6. Chen, C.-Y., Plummer, K. M., and Howlett, B. J. 1996. Ability of a Leptosphaeria maculans isolate to form stem cankers on Indian mustard (Brassica juncea) segregates as a single locus. Eur. J. Plant Pathol. 102:349-352.

7. Chen, W., and Muehlbauer, F. J. 2002. A mini-dome technique for virulence assay of Ascochyta rabiei on chickpea. Presented at the Proc.4th Can. Pulse Res. Workshop, Edmonton, Alberta, Canada.

8. Chen, W., and Muehlbauer, F. J. 2003. An improved technique for virulence assay of Ascochyta rabiei on chickpea. Int. Chickpea Pigeonpea Newsl. 10:31-33.

9. Chung, K.-R., Hollin, W., Siegel, M. R., and Schardl, C. L. 1997. Genetics of host specificity in Epichloe typhina. Phytopathology 87:599605.

10. Cisar, C. R., Spiegel, F. W., TeBeest, D. O., and Trout, C. 1994. Evidence for mating between isolates of Colletotrichum gloeosporioides with different host specificities. Curr. Genet. 25:330-335.

11. Cisar, C. R., Thornton, A. B., and TeBeest, D. O. 1996. Isolates of Colletotrichum gloeosporioides (Teleomorph: Glomerella cingulata) with different host specificities mate on Northern Jointvetch. Biol. Control 7:75-83.

12. Douhan, G. W., Peever, T. L., and Murray, T. D. 2002. Multilocus population structure of Tapesia yallundae in Washington State. Mol. Ecol. $11: 2229-2239$.

13. Fatehi, J., and Bridge, P. 1998. Detection of multiple rRNA-ITS regions in isolates of Ascochyta. Mycol. Res. 102:762-766.

14. Giraud, T., Villareal, L. M. M. A., Austerlitz, F., Le Gac, M., and Lavigne, C. 2006. Importance of the life cycle in sympatric host race formation and speciation of pathogens. Phytopathology 96:280-287.

15. Goodwin, S. B., and Fry, W. 1994. Genetic analyses of interspecific hybrids between Phytophthora infestans and Phytophthora mirabilis. Exp. Mycol. 18:20-32.

16. Goodwin, S. B., Legard, D. E., Smart, C. D., Morris, L., and Fry, W. 1999. Gene flow analysis of molecular markers confirms that Phytophthora mirabilis and P. infestans are separate species. Mycologia 91:796810 .

17. Gossen, B. D., Sheard, J. W., Beauchamp, C. J., and Morrall, R. A. A. 1986. Ascochyta lentis renamed Ascochyta fabae f. sp. lentis. Can. J. Plant Pathol. 8:154-160.

18. Heath, M. C. 1981. A generalized concept of host-parasite specificity. Phytopathology 71:1121-1123. 
19. Heath, M. C. 1991. The role of gene-for-gene interactions in the determination of host species specificity. Phytopathology 81:127-130.

20. Hiura, U. 1962. Hybridization between varieties of Erysiphe graminis. Phytopathology 52:664-666.

21. Hiura, U. 1978. Genetic basis of formae speciales of Erysiphe graminis. Pages 101-128 in: The Powdery Mildews. D. M. Spencer, ed. Academic Press, London.

22. Johnson, T. 1949. Intervarietal crosses in Puccinia graminis. Can. J. Res. 227:45-65

23. Jurgenson, J. E., Bowden, R. L., Zeller, K. A., Leslie, J. F., Alexander, N. J., and Plattner, R. D. 2002. A genetic map of Gibberella zeae (Fusarium graminearum). Genetics 160:1451-1460.

24. Kaiser, W. J. 1973. Factors affecting growth, sporulation, pathogenicity and survival of Ascochyta rabiei. Mycologia 65:444-457.

25. Kaiser, W. J. 1990. Host range of the Ascochyta blight pathogen of chickpea. (Abstr.) Phytopathology 80:889.

26. Kaiser, W. J. 1991. Host range studies with the Ascochyta blight pathogen of chickpea. Int. Chickpea Newsl. 25:25-27.

27. Kaiser, W. J. 1997. Inter- and intranational spread of Ascochyta pathogens of chickpea, faba bean and lentil. Can. J. Plant Pathol. 19:215-224.

28. Kaiser, W. J., Wang, B.-C., and Rogers, J. D. 1997. Ascochyta fabae and A. lentis: Host specificity, teleomorphs (Didymella), hybrid analysis, and taxonomic status. Plant Dis. 81:809-816.

29. Kang, S., Sweigard, J. A., and Valent, B. 1995. The $P W L$ host specificity gene family in the blast fungus Magnaporthe grisea. Mol. Plant-Microbe Interact. 8:939-948.

30. Khan, M. S. A., Ramsey, M. D., and Scott, E. S. 1999. Host range studies with an Australian isolate of Ascochyta rabiei. Aust. J. Agric. Res. 28:170-173.

31. Kohn, L. M. 2005. Mechanisms of fungal speciation. Annu. Rev. Phytopathol. 43:279-308.

32. Lee, S. B., and Taylor, J. W. 1990. Isolation of DNA from fungal mycelia and single spores. Pages 282-287 in: PCR Protocols: A Guide to Methods and Applications. M. A. Innis, D. H. Gelfand, J. J. Snisky, and T. J. White, eds. Academic Press, San Diego, CA.

33. Lemke, P. A. 2001. Speciation phenomena. Pages 219-227 in: The Mycota. Systematics and Evolution. Part B. Vol. VII. D. J. McLaughlin, E. G. McLaughlin, and P. A. Lemke, eds. Springer-Verlag, Berlin.

34. Martinez, J. P., Groth, J. V., and Young, N. D. 1994. Segregation and phylogenetic data suggest speciation may be occurring within Uromyces appendiculatus. (Abstr.) Phytopathology 84:1096.

35. Martinez, J. P., Groth, J. V., and Young, N. D. 1996. Non-Mendelian and skewed segregation of DNA markers in wide crosses of the bean rust fungus, Uromyces appendiculatus. Curr. Genet. 29:159-167.

36. Mel'nik, V. A., Braun, U., and Hagedorn, G. 2000. Key to the Fungi of Genus Ascochyta Lib. (Coelomycetes). Arno Brynda, Kurfustendamm, Berlin.

37. Milgroom, M. G. 1996. Recombination and the multilocus structure of fungal populations. Annu. Rev. Phytopathol. 34:457-477.

38. Milgroom, M. G., and Fry, W. E. 1997. Contributions of population genetics to plant disease epidemiology and management. Adv. Bot. Res. 24:1-30.

39. Murakami, J., Tomita, R., Kataoka, H., Nakayashiki, H., Tosa, Y., and Mayama, S. 2003. Analysis of host species specificity of Magnaporthe grisea toward foxtail millet using a genetic cross between isolates from wheat and foxtail millet. Phytopathology 93:42-45.

40. Nelson, R. R., and Kline, D. M. 1969. Genes for pathogenicity in Cochliobolus heterostrophus. Can. J. Bot. 47:1311-1314.

41. Nelson, R. R., and Kline, D. M. 1969. The identification of genes for pathogenicity in Cochliobolus carbonum. Phytopathology 59:164-167.

42. Nene, Y. L., Hanounik, S. B., Qureshi, S. H., and Sen, B. 1988. Fungal and bacterial foliar diseases of pea, lentil, faba bean and chickpea. Pages 577-589 in: World Crops: Cool Season Food Legumes. R. J. Summerfield, ed. Kluwer Academic Publishers, Dordrecht, The Netherlands.

43. Nene, Y. L., and Reddy, M. V. 1987. Chickpea diseases and their control. Pages 233-270 in: The Chickpea. M. C. Saxena and R. S. Singh, eds. CAB International, Wallingford, Oxfordshire, UK

44. Olson, A., and Stenlid, J. 2002. Pathogenic fungal species hybrids infecting plants. Microbes Infect. 4:1353-1359.
45. Pedersen, C., Rasmussen, S. W., and Giese, H. 2002. A genetic map of Blumeria graminis based on functional genes, avirulence genes, and molecular markers. Fungal Genet. Biol. 35:235-246.

46. Pedley, K. F., and Martin, G. B. 2003. Molecular basis of Pto-mediated resistance to bacterial speck disease in tomato. Annu. Rev. Phytopathol. 41:215-243.

47. Peever, T. L., Barve, M. P., and Kaiser, W. J. 2002. Molecular systematics of Ascochyta spp. infecting legumes. Presented at the 7th Int. Mycol. Congress, Oslo, Norway.

48. Peever, T. L., Canihos, Y., Olsen, L., Ibanez, A., Liu, Y. C., and Timmer, L. W. 1999. Population genetic structure and host specificity of Alternaria spp. causing brown spot of Minneola tangelo and rough lemon in Florida. Phytopathology 89:851-860.

49. Peever, T. L., Hernandez-Bello, M. A., Barve, M. P., and Kaiser, W. J. 2005. Evolution of Ascochyta spp. on wild and cultivated legumes. Presented at the 23rd Fungal Genet. Conf. Asilomar, CA.

50. Peever, T. L., Hernandez-Bello, M. A., and Kaiser, W. J. 2003. Genetics of host specificity of Ascochyta spp. infecting legumes. Presented at the 3rd Annu. Meet. Fungal Mol. Biol. Soc. Jpn., Tokyo.

51. Peever, T. L., Salimath, S. S., Kaiser, W. J., and Muehlbauer, F. J. 2004. Historical and contemporary multilocus population structure of Ascochyta rabiei (teleomorph: Didymella rabiei) in the Pacific Northwest of the United States. Mol. Ecol. 13:291-309.

52. Perkins, D. D. 1994. How should the infertility of interspecific crosses be designated? Mycologia 86:758-761.

53. Pimentel, G., Carris, L. M., and Peever, T. L. 2000. Characterization of interspecific hybrids between Tilletia controversa and T. bromi. Mycologia 92:411-420.

54. Pringle, A., and Taylor, J. W. 1992. The fitness of filamentous fungi. Trends Microbiol. 10:474-481.

55. Rivas, S., and Thomas, C. M. 2005. Molecular interactions between tomato and the leaf mould pathogen Cladosporium fulvum. Annu. Rev. Phytopathol. 43:395-436.

56. Schardl, C. L., and Craven, D. 2003. Interspecific hybridization in plantassociated fungi and oomycetes: A review. Mol. Ecol. 12:2861-2873.

57. Sweigard, J. A., Carroll, A. M., Kang, S., Farrall, L., Chumley, F. G., and Valent, B. 1995. Identification, cloning, and characterization of PWL2, a gene for host species specificity in the rice blast fungus. Plant Cell 7:1221-1233.

58. Takabayashi, N., Tosa, Y., Oh, H. S., and Mayama, S. 2002. A gene-forgene relationship underlaying the species-specific parasitism of Avena/ Triticum isolates of Magnaporthe grisea on wheat cultivars. Phytopathology 92:1182-1188.

59. Taylor, J. W., Jacobson, D. J., Kroken, S., Kasuga, T., Geiser, D. M., Hibbett, D. S., and Fisher, M. C. 2000. Phylogenetic species recognition and species concepts in fungi. Fungal Genet. Biol. 31:21-32.

60. Trapero-Casas, A., and Kaiser, W. J. 1992. Development of Didymella rabiei, the teleomorph of Ascochyta rabiei, on chickpea straw. Phytopathology 82:1261-1266.

61. Tripathi, H. S., Singh, R. S., and Chaube, H. S. 1987. Host-range of Ascochyta rabiei (Pass.) Labr., the causal agent of Ascochyta blight in chickpea. Int. Chickpea Newsl. 16:11.

62. Tzeng, T.-H., Lyngholm, L. K., Ford, C. F., and Bronson, C. R. 1992. A restriction fragment length polymorphism map and electrophoretic karyotype of the fungal maize pathogen Cochliobolus heterostrophus. Genetics 130:81-96.

63. Valent, B., Farral, L., and Chumley, F. G. 1991. Magnaporthe grisea genes for pathogenicity and virulence identified through a series of backcrosses. Genetics 127:87-101.

64. Vos, P., Hogers, R., Bleeker, M., Reijans, M., Van de Lee, T., Hornes, M., Frijters, A., Pot, J., Peleman, J., Kuiper, M., and Zabeau, M. 1995. AFLP: A new technique for DNA fingerprinting. Nucleic Acids Res. 23:44074444.

65. Wilson, A. D., and Kaiser, W. J. 1995. Cytology and genetics of sexual compatibility in Didymella rabiei. Mycologia 87:795-804.

66. Zhong, S., Steffenson, B. J., Martinez, J. P., and Ciuffetti, L. M. 2002. A molecular genetic map and electrophoretic karyotype of the plant pathogenic fungus Cochliobolus sativus. Mol. Plant-Microbe Interact. 15:481492. 